\title{
Probing the Inhibitory Mechanism of Calcite Precipitation by Organic Phosphonates in Industrial Water Cooling System
}

\author{
Mingzhu Xia and Chunyu Chen
}

\begin{abstract}
The effect of three phosphonic acids (ethylene diamine tetra (methylene phosphonic acid), EDTMP; hexamethylene diamine tetra (methylene phosphonic acid), HDTMP; and diethylene triamine penta (methylene phosphonic acid), DTPMP on the growth of $\mathrm{CaCO}_{3}$ has been investigated by pH curve method (pHCM). The result shows the inhibitor effectiveness: DTPMP > EDTMP > HDTMP. Meanwhile, the interaction of three phosphonic acids with the calcite (104) surface has been also studied by means of molecular dynamic simulation under the periodic boundary condition in industrial water environment. The results indicate that strong electrostatic interactions between the oxygen atom in phosphonate functional groups and the $\mathrm{Ca}^{2+}$ of the calcite (104) face play a dominant role in their adsorption. For the calcite (104) surface, the binding energy has a sequence in agreement with the $\mathrm{pHCM}$ experiment. The weakest inhibition of $\mathrm{CaCO}_{3}$ is HDTMP because of the only one phosphonate group in contact well with the surface.
\end{abstract}

Index Terms-Phosphonate, pH curve method, inhibition, molecular dynamic simulation.

\section{INTRODUCTION}

The precipitation of calcium carbonate is of fundamental importance in great many researches for instance medicine, industry, and households [1]-[3]. Calcium carbonate particles are found as different polymorphs, consisting of calcite, aragonite, vaterite, calcium carbonate monohydrate and calcium carbonate hexahydrate [4]. Among them, calcite is by far the most stable phase under normal atmospheric conditions, and is extensively investigated as a scale product in many industrial processes [5]. The (104) surface is the most stable plane of calcite and dominates the observed morphology [6], [7].

Phosphonate additives are often used to inhibit the formation of this scale in industrial water cooling system [8], [9]. Phosphonates have a strong tendency to adsorb onto a variety of surfaces, e.g., calcite [10], barite [11] and iron oxides [12].

To date, more relevant studies have concentrated on understanding the dominant mechanisms of calcite crystal growth in the presence of inhibitors. It appears, for instance, that the ionization of the phosphonate group is significant;

Manuscript received April 13, 2014; revised July 17, 2014

Mingzhu Xia is with the Department of Chemistry, Nanjing University of Science and Technology, Nanjing, PR China (e-mail: dong7321@ 163.com).

Chunyu Chen is with the Department of Metallurgy and Material Engineering, Jiangsu University of Science and Technology, Zhangjiagang, PR China (e-mail: ccyzhj1214@163.com). that is, a deprotonated phosphonate molecule inhibits precipitation more strongly [11]. Gill et al. have proposed the theory of lattice matching that there is a link between the mineral lattice and the functional group spacing which dominates inhibitory power [13].

Moreover, Franca et al. have studied the adsorption of two phosphonate groups from different amine groups on barite crystal. It has been found that both stereochemical hindrance and complexation strength differences results in different inhibitory power [14]. Bromley et al. investigated the effect of chain length between the two phosphonates. They found that the greastest inhibition of barite growth occurred when the link was greater than $6 \AA$ A. C. M. Pina presented the effect of five phosphonic acid on the growth of barite (001) using atomic force microscopy (AFM), and indicated that only kink sites along monomolecular steps can be considered as possible inhibition sites [15]. Molecular modeling could also been used to identify organo metallic interaction [16]. Ibrahim has studied the effect of industrial waste disposal south of Cairo on the molecular structure of Nile River sediment by both Fourier transform infrared spectroscopy (FT-IR) and density functional theory (DFT) [17].

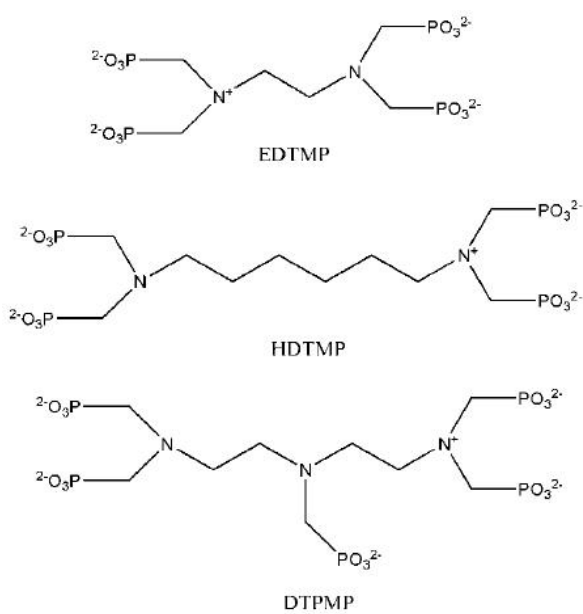

Fig. 1. Structures of depronated phosphonic acids at $\mathrm{pH}$ around 8.

In previous work, the interaction of three phosphonates (EDTMP, HDTMP and DTPMP) with calcite surfaces was examined by both the $\mathrm{pH}$ curve method and molecular dynamic simulation in the absence of water molecules [18]. The results show that phosphonates have a high affinity for calcite. But the stimulant conditions don't conform to the actual circulating water system. The aim of this work described here is to investigate the effect of molecular adsorption of the three phosphonates on calcite (104) surface using the same method in an alkalescent industrial water 
environment. EDTMP and HDTMP have four phosphonate functional groups attached to amine nitrogen atoms through methylene chain. The only difference is the length of the backbone methylene chain. But DTPMP has five phosphonate groups attached to three $\mathrm{N}$ atoms. The structures (see in Fig. 1) are deprotonated referring to the $\mathrm{pH}$ values in the range of $7-8$ in an alkalescent industrial water environment.

\section{EXPERIMENT}

\section{A. Materials}

$\mathrm{CaCl}_{2}$ (AR grade, Nanjing Chemical Regent CO., LTD); $\mathrm{NaHCO}_{3}$ (AR grade, Shanghai LingFeng Chemical Regent CO., LTD); EDTMP, HDTMP and DTPMP are commercial samples from Shangdong Zaozhuang Xudong Chemical Regent CO., LTD.

A PHS- $3 \mathrm{C} \mathrm{pH}$ meter from Shanghai Precision Scientific Instrument CO., LTD and a 78-1 magnetic heating stirrer from Jintan Jiangnan Instrument CO., LTD were seperately used for $\mathrm{pH}$ measurement and stirring.

\section{B. The pH Curve Method ( $p H C M$ )}

The concentration of $\mathrm{OH}^{-}$increases owing to escape of $\mathrm{CO}_{2}$ by stirring. The precipation of $\mathrm{CaCO}_{3}$ occurs, when $\mathrm{OH}^{-}$ reacts with $\mathrm{HCO}_{3}{ }^{-}$. Consequently, the $\mathrm{pH}$ value drops due to the formation of $\mathrm{CaCO}_{3}$ scale (seen in (1)).

$$
\begin{aligned}
& \mathrm{OH}^{-}+\mathrm{HCO}_{3}^{-} \rightleftharpoons \mathrm{CO}_{3}^{2-}+\mathrm{H}_{2} \mathrm{O} \\
& \mathrm{Ca}^{2+}+\mathrm{CO}_{3}^{2-} \rightleftharpoons \mathrm{CaCO}_{3} \downarrow
\end{aligned}
$$

$250 \mathrm{~mL}$ of stable supersaturated solution of calcium carbonate $(8 \mathrm{mmol} / \mathrm{L})$ was prepared by the addition of a known volume of calcium chloride solution $(0.1 \mathrm{~mol} / \mathrm{L})$ and sodium bicarbonate $(0.2 \mathrm{~mol} / \mathrm{L})$. The mixed solutions were measured of $\mathrm{pH}$ values after the addition of a range of different concentrations of the phosphonate acids at the temperature of $25^{\circ} \mathrm{C}$.

\section{Molecular Dynamics (MD) Simulation Method}

The space group of calcite, is $\mathrm{R}-3 \mathrm{C}$ and its lattice parameters are $a=b=4.99 \AA, c=17.06 \AA, \alpha=\beta=90.0^{\circ}, \gamma=$ $120.0^{\circ}$. Calcite crystallographic surface was built by cleaving along the (104) face, followed by minimized using Newton under the periodic boundary conditions with a non-bond cutoff distance of $9.5 \AA$.

We have simulated the three deprotonated nitrogencontaining phosphonates EDTMP $^{7_{-}}, \mathrm{HDTMP}^{7_{-}^{-}}$and $\mathrm{DTPMP}^{9-}$ ) onto the calcite (104) face in industrial water environment using Materials Studio v3.0 (MS) under compass force field used in the previous studies [19]. Simulation details of MD are shown in Table I.

The strength of interaction of the surface with the inhibitor is shown by binding energy, calculated according to (2):

$$
E_{\text {bind }=}-\left(\mathrm{E}_{\text {system }}-\mathrm{E}_{\text {inhibitor+waterte }}-\mathrm{E}_{\text {surface }+ \text { water }}+\mathrm{E}_{\text {water }}\right)
$$

where $\mathrm{E}_{\text {system }}$ is the total energy of the simulation system, $\mathrm{E}_{\text {surface+water }}$ is the energy of the surface with water,
$\mathrm{E}_{\text {inhibitor+waterte }}$ is the energy of the free inhibitor moelcule with water, and $\mathrm{E}_{\text {water }}$ is the energy of the free water molecule after calculation.

TABLE I: SIMULATION DETAILS OF MD

\begin{tabular}{ll}
\hline Simulation parameter & value \\
\hline Force field & Compass \\
Non-bond & Vdw, Coulomb \\
Ensemble & NVT \\
Thermostat & Berendsen \\
Time step & $1 \mathrm{fs}$ \\
Frame output & 100 \\
Dynamic time & $500 \mathrm{ps}$ \\
Cut-off distance & $0.95 \mathrm{~nm}$ \\
Dielectric constant & 78.0 \\
Summation method & Atom Based \\
Simulation temperature & $350 \mathrm{~K}$ \\
Minimization & Smart Minimizer \\
Convergence level & Medium \\
Maximum iterations & 5000 \\
Energy deviation & $5000 \mathrm{kal} / \mathrm{mol}$ \\
Number of Steps & 500000 \\
Production Steps & $15 \mathrm{ps}$ \\
Decay constant & $0.1 \mathrm{ps}$ \\
\hline \hline
\end{tabular}

\section{RESULTS AND DISCUSSIONS}

\section{A. The pHCM Exprements}

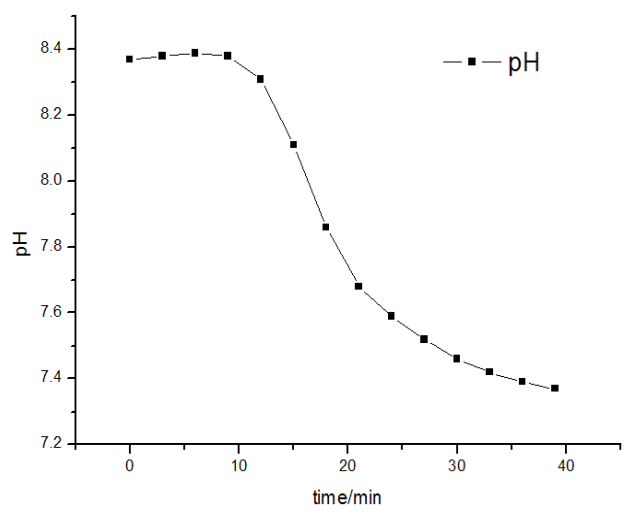

Fig. 2. The $\mathrm{pH}$ value in the absence of the phosphonates.

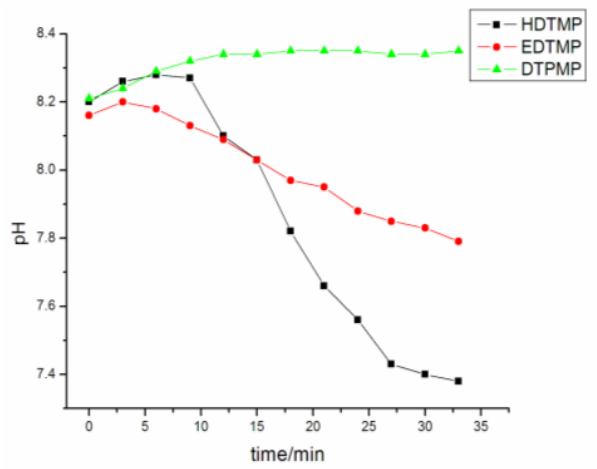

Fig. 3. the $\mathrm{pH}$ values in presence of the phosphonates at the concentration of $0.0002 \mathrm{mmol} / \mathrm{L}$.

The pHCM exprements have been performed in the presence of the three phosphonates. Fig. 2 shows the $\mathrm{pH}$ value speedily raised in the absence of the phosphonates in ten minutes, afterwards decreased rapidly that indicates the growth of $\mathrm{CaCO}_{3}$ sediment. In order to qualitatively analyze the inhibiting effect of the EDTMP, HDTMP, and DTPMP, the $\mathrm{pH}$ values of the mixed solutions are measured after the 
addition of the inhibitors in different concentrations $(0.0001 \mathrm{mM} \sim 0.0004 \mathrm{mM})$. For direct elucidation, it only shows the $\mathrm{pH}$ values at the inhibitor concentration of $0.0002 \mathrm{mM}$ in Fig. 3.

When $0.0002 \mathrm{mmol} / \mathrm{L}$ concentrations are employed, $\mathrm{pH}$ slowly raised. Hence, the inhibition of $\mathrm{CaCO}_{3}$ growth by DTPMP is fully successful. At the same concentration, the $\mathrm{pH}$ decrease of HDTMP is faster than EDTMP; that is, the inhibition effect of HDTMP is weaker than EDTMP.

\section{B. Interaction of Deprotonated Phosphonates with the Calcite (104) Face in Water}

In order to conform to the aqueous medium of industrial water treatment, the movement and effect of water in the total system has been considered by means of setting the permittivity (dielectric constant, $\varepsilon$ ) and adding water molecules. In this paper, $\varepsilon$ is set of 78.0 and a mass of water molecules are added to each surface of calcite according with water environment.

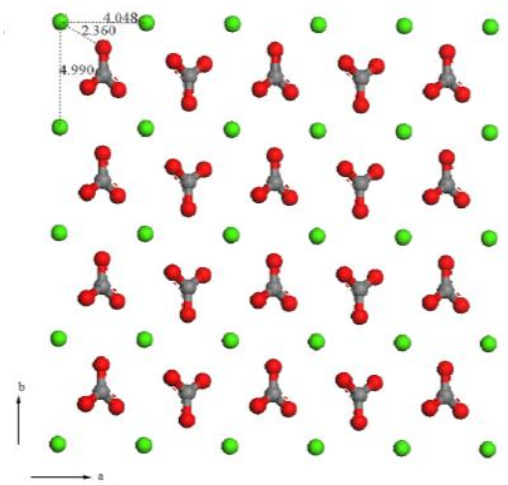

Fig. 4. Top view of the calcite(104) face. Color codes: calcuim atom= green; carbon atom $=$ grey; oxygen atom $=$ red.

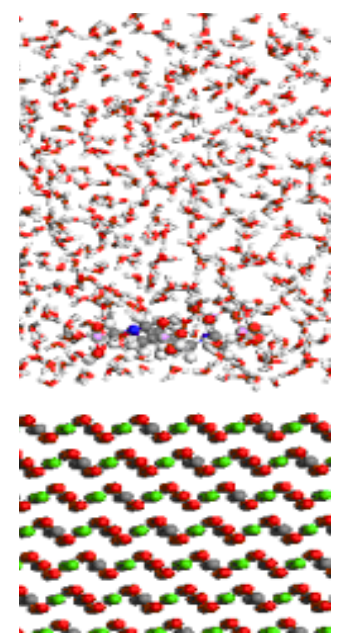

Fig. 5. Side view of original state on calcite (104) face.

The $\mathrm{Ca}-\mathrm{Ca}$ distances of the calcite (104) surface are separately $4.048 \AA$ and $4.990 \AA$; the Ca-O length is $2.360 \AA$ (Fig. 4). All the three phosphonate acids were also first minimized by the same minimization method before doing MD simulations. The vacuum chamber is divided into three parts. More specifically, the vacuum is at the top; water molecules and scale inhibitor are in the middle of the box, while the calcite (104) surface is at the bottom. The simulative dimensions of vacuum brake are $24.28 \AA \times 19.96$ $\AA \times 86.27 \AA$, and $\alpha=\beta=\gamma=90^{\circ}$. There are approximately 2400 atoms in the box, for instance, shown in Fig. 5. We have separately considered the interaction of three phosphonate acids with the calcite (104) face. In Fig. 6, it clearly shows all of the phosphate molecules point towards the calcite (104) surface instead of water molecules. The results suggest that the phosphonates interact well with the calcite (104) surface on account of its oxygen atoms of phosphate group contacting well with calcium ions on the surface.

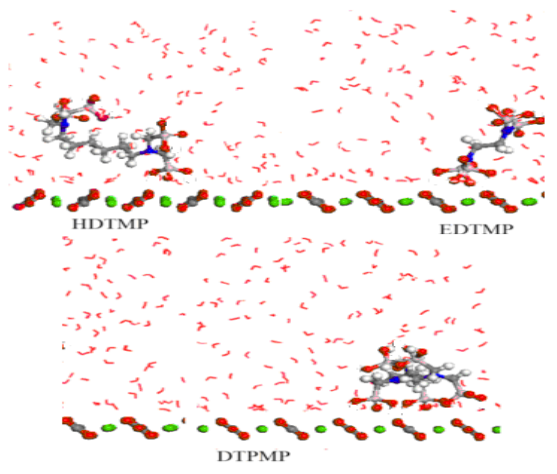

Fig. 6. Side view of 3 compounds adsorption on the calcite (104) surface.

Both EDTMP and HDTMP have four phosphonate functional groups attached to amine $\mathrm{N}$ atoms. The only difference is the length of the backbone methylene chain connecting the two $\mathrm{N}$ atoms. Bromley et al. recognize that one of the amine groups "approaches" the barite crystal surface [20]. It has been seen from the above images that one of the amine groups of two phosphonates interacts with the calcite surface.

In particular, only one phosphonate group of HDTMP has been adsorbed on the face owing to the methylene chain bending itself, while two phosphoante groups are absorbed in EDTMP. Both EDTMP and HDTMP have four phosphonate functional groups attached to amine $\mathrm{N}$ atoms. More importantly, the potency varies with the length of alkyl chain connecting the two $\mathrm{N}$ atoms, which induces the effect: EDTMP > HDTMP. It might be that the length of the backbone chain is too longer to increase the steric hindrance. The length of the backbone chain in HDTMP is $9.077 \AA$, whereas the length in EDTMP is $3.114 \AA$ A. DTPMP has five phosphonate groups, and three of them "approach" the surface. Thus, the greater the number of phosphonate groups, the greater the inhibition of scale formation.

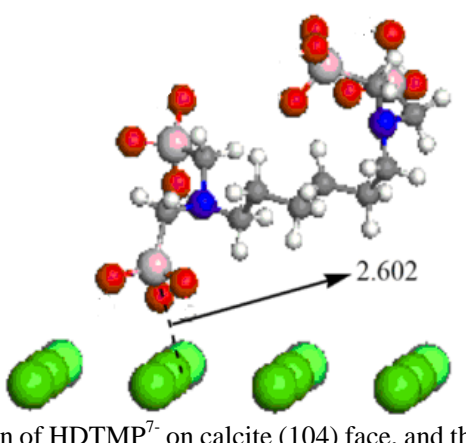

Fig. 7. Adsorption of HDTMP ${ }^{7-}$ on calcite (104) face, and the combination of $\mathrm{Ca}^{2+}$ with oxygen atom.

It has been found that, in general, the dominant mechanism of interaction for the additives on calcite is via the deprotonated groups with calcium ions on the surface. For 
example, Fig. 7 displays the adsorbed mode of HDTMP on the calcite (104) surface and the combination of $\mathrm{Ca}^{2+}$ with oxygen atom. The $\mathrm{Ca}-\mathrm{O}(\mathrm{P})$ distances are about $2.6 \AA$ in accordance with the $\mathrm{Ca}-\mathrm{O}$ bond length in experience, while the distances are separately $2.52 \AA$ and $2.67 \AA$ in EDTMP, and $2.47 \AA, 2.55 \AA, 2.63 \AA$ in DTPMP. Apparently, DTPMP has the most significant inhibition effect compared with the remaining two phosphonate additives.

For further analysis of the effectiveness of inhibition, we consider the binding energy of interaction between the three phosphonate molecules and the calcite (104) surface in the aqueous phase listed in Table II. It clearly indicates the energy of interaction is dominated by electrostatic interaction, whereas the van der Waals interaction plays a very small role in the non- bonded interaction. Based on the data in Table II, the interaction energy is exothermic and the effectiveness of inhibiton is DTPMP> EDTMP> HDTMP in agreement with the $\mathrm{pH}$ curve experimental result. Hence, it has been proved that molecular modeling can predict the phosphonate's ability to inhibit precipitation under the simulation details. In short, inhibition could be tested easily and more cheaply on computers than by experiment.

TABLE II: ENERGIES BETWEEN 3 COMPOUNDS AND CALCITE (104) SURFACE (UNIT: EV)

\begin{tabular}{lllll}
\hline \hline Molecule & $\mathrm{E}_{\mathrm{vdw}}$ & $\mathrm{E}_{\text {coulomb }}$ & $\mathrm{E}_{\text {nonbond }}$ & $E_{\text {bind }}$ \\
\hline \hline HDTMP & -2.04 & -39.12 & -41.18 & 42.57 \\
EDTMP & -2.50 & -63.63 & -66.15 & 67.64 \\
DTPMP & -2.45 & -95.37 & -97.86 & 99.95 \\
\hline \hline
\end{tabular}

It is noted that there is a strongest adsorption peak at the range from $2 \AA$ to $3 \AA$ (Fig. 8) which indicates the interaction between the calcium atoms and the oxyen atoms in inhibitors. Our these findings are consistent with the above analysis.

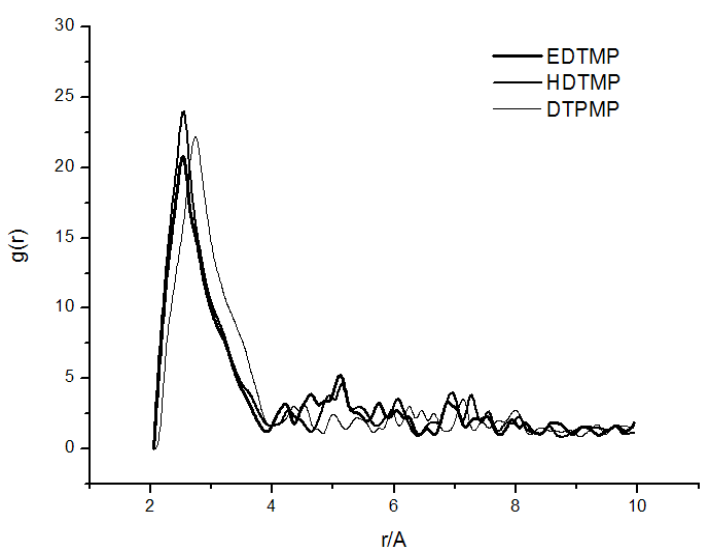

Fig. 8. Pair correlatiom function of oxygen atoms in inhibitors with calcium atoms in calcite (104) surface.

\section{CONCLUSION}

This work is a study of molecular interaction between phosphonate acids with calcite in presence of water. In summary, organic phosphonates have a significant effect on precipitation. Both the $\mathrm{pHCM}$ experiments and molecular dynamics simulation method have proved the conclusion that the inhibition of three organic phosphonates is DTPMP > EDTMP > HDTMP according to their group number and the length of the backbone methylene chain. It also indicates the energy of interaction is dominated in electrostatic interaction, whereas the van der Waals interaction plays a very small role in the non- bonded interaction. This paper provides an easy and cheap means to determine the inhibition potency of additives. Future work will focus on studies of the interaction of phosphonates with the aragonite and vaterite surfaces in presence of water and the interaction of the calcite stepped surfaces with phosphonates in presence of $\mathrm{Na}^{+}$or $\mathrm{Zn}^{2+}$ ions.

\section{ACKNOWLEDGMENTS}

This work is supported by Institute of Industrial Chemistry, Nanjing University of Science \& Technology. The help of Dr. Wang in performing the simulations is kindly acknowledged.

\section{REFERENCES}

[1] V. Tantayakom, T. Sreethawong, and H. S. Fogler, "Scale inhibition study by turbidity measurement," J. Colloid Interface Sci., vol. 284, no. 1 , pp. 57-65, 2005

[2] F. Manoli and E. Dalas, "Calcium carbonate crystallization in the presence of glutamic acid," J. Cryst. Growth, vol. 222, pp. 293-296, 2001.

[3] D. Lisitsin, D. Hasson, and R. Semiat, "Modeling the effect of antiscalant on $\mathrm{CaCO}_{3}$ precipitation in continuous flow," Desalination \& Water Treatment, vol. 1, pp. 17-24, 2009.

[4] A. J. Xie, Y. H. Shen et al., "Crystal growth of calcium carbonate with various morphologies in different amino acid systems," J. Cryst. Growth, vol. 285, pp. 436-443, 2005.

[5] M. M. Reddy and A. R. Hoch, "Calcite crystal growth rate inhibition by polycarboxylic acid," J. Colloid Interface Sci., vol. 236, pp. 365-370, 2001.

[6] F. Manoli, J. Kanakis, P. Malkaj, and E. Dalas, "The effect of aminoacids on the crystal growth of calcium carbonate," J. Cryst. Growth, vol. 236, pp. 363-370, 2002.

[7] K. I. Parsiegla and J. L. Katz, "Calcite growth inhibition by cooper (II) -An introduction, holt," J. Cryst. Growth, vol. 200, pp. 213-226, 1999

[8] M. M. Reddy and G. H. Nancollas, "Calcite crystal growth inhibition by phosphonate," Desalination, vol. 12, pp. 61-73, 1983.

[9] G. J. Ralph, R. Kevin, and W. Brian, "Effect of phosphonate inhibitors on calcite nucleation kinetics as a function of temperature using light scattering in an autoclave," Chemical Geology, vol. 132, pp. 215-225, 1996.

[10] B. R. Pradip and T. K. Rao, "Molecular modeling of interactions of diphosphonic acid based surfactants with calcium minerals," Langmuir, vol. 18, pp. 932-940, 2002.

[11] J. Franca, R. R. Willian, and L. R. Andrew, "Molecular modeling of phosphonate molecules onto barium sulfate terraced surfaces," J. Phys. Chem. B., vol. 110, pp. 7414-7424, 2006.

[12] T. S. Anirudhan, S. Rijith, and C. D. Bringle, "Iron complex of an amino-functionalized poly(acrylamide)-grafted lignocellulosic residue as a potential adsorbent for the removal of chromium from water and industry effluents," Desalination \& Water Treatment, vol. 12, pp. 3-15, 2009.

[13] J. S. Gill and R. G. Varsanik, "Computer modeling of the specific matching between scale inhibitors and crystal structure of scale forming minerals," J. Cryst. Growth, vol. 76, pp. 57-62, 1986.

[14] E. Barouda, K. D. Demadis, S. R. Freeman, and F. Jones, "Barium sulfate crystallization in the presence of variable chain length aminomethylenetetraphosphonates and cations $\left(\mathrm{Na}^{+}\right.$or $\left.\mathrm{Zn}^{2+}\right)$," Gryst. Growth \& Design, vol. 7, pp. 321-327, 2007.

[15] C. M. Pina, C. V. Putnis, U. Becker, S. Biswas, E. C. Carroll, D. Bosbach, and A. Putnis, "An atomic force microscopy and molecular simulations study of the inhibition of barite growth by phosphonates," Surface Science, vol. 553, pp. 61-74, 2004.

[16] M. Ibrahim, "Molecular spectroscopic study of acid treated fenugreek seeds," Spectrochimica Acta. Part A, vol. 77, pp. 1034-1038, 2010.

[17] M. Ibrahim, A. J. Hameed, and A. Jalbout, "Molecular spectroscopic study of river Nile sediment in the greater Cairo region," Applied Spectroscopy, vol. 62, no. 3, pp. 306-311, 2008.

[18] C. Y. Chen, M. Z. Xia, and F. Y. Wang, "Influence of three organic phosphonates on calcite crystal growth," Advanced Materials Research, vol. 154-155, pp. 437-442, 2010. 
[19] C. Y. Chen, M. Z. Xia, W. Lei, C. Zhou, and F. Y. Wang, "Modeling the interaction of seven bisphosphonates with the hydroxyapatite(100) face," J. Mol. Model, vol. 18, no. 9, pp. 4007-4012, 2012.

[20] L. A. Bromley, D. Cottier, and R. J. Davey, "Interactions at the organic/ inorganic interface: Molecular design of crystallization inhibitors for barite," Langmuir, vol. 9, pp. 3594, 1999.

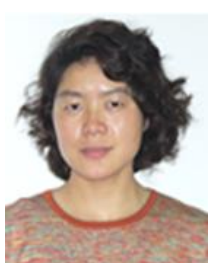

Mingzhu Xia was born in Wuhan, Hubei, P. R. China on August 7, 1968. Mrs Xia earned her Ph.D. degree of applied chemistry from Nanjing University of Science $\&$ Technology.

She works as a researcher in Water Treatment Institute (now named Institute of Industrial Chemistry) in College of Chemical Engineering of Nanjing University of Science \& Technology. She has been engaged in researching in the fields of the relationship between structure and function of the organic compounds containing phosphor and of low polymers, and the controlling of water quality in industry. She has completed more than twenty projects from enterprises and the government of state departments and provinces. She has published one hundred of papers.

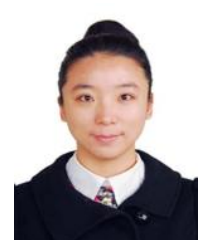

Chunyu Chen was born in Nantong, Jiangsu, P. R China on April 9, 1986. Mrs Chen earned her Ph.D. degree of materials science and engineering from Nanjing University of Science \& Technology.

Now she works as a teacher in College of Metallurgy and Material Engineering of Jiangsu University of Science and Technology (Zhangiagang). She has been engaged in researching the relationship between structure and function of the organic compounds containing phosphor and of low polymers for more than 5 years. 